\title{
El Atlántico, paradigma de la novedad en la época del renacimiento. Imaginario y realidad
}

Carlos Alberto González Sánchez

Resumen: Escribir lo visto y oído en los nuevos mundos, fue objeto de un despliegue informativo a escala planetaria durante el Renacimiento. Las noticias de aquellos acontecimientos, reales o imaginarias, sin duda fueron esenciales para afrontar el impacto de América en Europa, sus prodigios y maravillas. En un tiempo apasionado con las novedades y el descubrimiento de la Naturaleza. Tal vez el origen de una incipiente "globalización" resultante de la proyección del Atlántico en el Pacífico. Una secuencia histórica capaz de menguar las incertidumbres y distancias de semejante reto para el Viejo Continente. Por ello rebasar los límites entre lo cierto y lo dudoso, fue una de las mayores aspiraciones de unas gentes que apreciaron lo asombroso como la antesala del conocimiento. Palabras claves: Renacimiento, Ciencia, Maravilla, Información, Novedad.

El descubrimiento y conquista de nuevos mundos fue uno de los grandes acontecimientos del Renacimiento, una época de cambios impactantes, entusiasmada con sus invenciones, deseosa de novedades y de saber más sobre el universo ${ }^{1}$. Aquella promoción de Occidente, una ofensiva frente al Oriente, desencadenó una inusitada curiosidad hacia lo alejado, exótico y desconocido; os móviles que hicieron posible la ruptura de unas fronteras geográficas, hasta entonces insalvables, en las que los antiguos proyectaron un cúmulo

\footnotetext{
* Professor Catedrático de Historia Moderna da Universidad de Sevilla. E-mail: calberto@us.es
}

Anos 90, Porto Alegre, v. 24, n. 45, p. 23-44, jul. 2017 
de anhelos, esperanzas y miedos. Descubrir era viajar, un proceso vital que ofrecía a sus artífices la posibilidad de presenciar y conocer el mundo exterior, al menos desde una percepción individual o subjetiva que, a la vez, experimenta la inevitable transformación mental inherente al contacto con realidades al margen de lo cotidiano.

Por ello, rebasar los límites entre lo cierto y lo dudoso, entre lo real y lo imaginario o mítico, desde el siglo XIII se había convertido en una de las grandes aspiraciones de unos hombres que, gracias a los griegos, apreciaron el asombro como el principio del conocimiento. Más allá de los abismos, del agua y de la tierra, estaban los tesoros, monstruos y prodigios que durante tanto tiempo los clásicos, sin llegar a verlos nunca, recrearon y soñaron. Los europeos del Quinientos, gracias al enorme cúmulo informativo que lograron reunir de los novedosos continentes, de los abismales límites superados, pudieron imponer su hegemonía en la Tierra y estructurar los imperios coloniales de la Modernidad ${ }^{2}$. Aunque no menos determinante, en una época preindustrial, fue la, a nuestros ojos, impresionante y diligente circulación jamás vista de hombres y noticias a escala planetaria, el principio, dicen algunos, de la mundialización actual. De ahí que el humanista milanés Pedro Mártir (1457-1526), el primer historiador de lo que él denominó Nuevo Mundo, sin moverse de la España de los Reyes Católicos, y debido a las noticias que recibía de los acontecimientos ultramarinos, tuviese la impresión de "estar recorriendo el mundo entero, e imaginar ser en la Corte un ciudadano universal, porque aquí estudio a fondo cuanto sucede en la redondez de la Tierra" (MÁRTIR, 1953-1957, v. 1, p. 356; 1989).

Este fenómeno precipitó en el mundo ibérico una sucesión ininterrumpida de descubrimientos y, acto seguido, una expansiva dominación militar, política y económica en el mundo. No de menor impronta fue la acumulación de nuevos saberes e información, de todo tipo y origen, y el tráfico continuo de seres, objetos, mercancías y creencias. S. Gruzinski (2007, 2010), en semejante movilización universal, además distingue consecuencias de gran impacto como la generalización de mestizajes vinculada con el tránsito de conocimientos, prácticas e imaginarios, una de las causas del enfrentamiento de modos de vida, tradiciones y sistemas de pensamiento diferentes que este proceso provocó. 
En el imaginario occidental, el Atlántico, la mar océana, realzaba la distancia, geográfica e intelectual, entre el mundo conocido y los que se estaban descubriendo. Por ello se convirtió en un limes difícil de aprehender para los europeos, generador de ilusiones y victorias espirituales y materiales. M. Foucault (1984) vería en él una de sus heterotopías, o sea, un espacio real, mágico y extraño al mismo tiempo, en tanto que incomprensible y, a la vez, capaz de resolver algunas de las grandes incógnitas culturales de la vieja Europa. Aquella desenfrenada búsqueda de rutas oceánicas y continentales, quimeras y tesoros, generó un inusitado piélago de aventuras y trances vitales, muchas veces más fabulosos que los narrados en los entonces muy exitosos libros de caballería. La perplejidad de sus protagonistas les llevó a creer que todo era resultado de embeleco u otras artes del demonio; o de la melancolía inherente al distanciamiento de los quehaceres cotidianos, una suerte de maléfica tristeza sin causa y de facultad imaginativa de la que todos temían un perverso síntoma: la incapacidad de distinguir entre lo natural y lo sobrenatural.

Pero siguiendo la estela de la Antigüedad y de otros que les precedieron, los protagonistas de la aventura oceánica, cautelosos con las habladurías de curiosos, pusieron por escrito lo que vieron o creyeron ver; de este modo harían verosímiles los hechos a los que los leyeren u oyeren y, de paso, a ellos mismos, ejecutores de unas gestas que, a menudo, atribuían a una nebulosa gama de ensueños y encantamientos propia de las misteriosas jornadas rumbo a lo desconocido que resistieron. En las fechas cierto era todo aquello que se manifestaba y fijaba, pese al transcurrir de los días y las noches, mediante la escritura en un soporte material. Aquí está la causa de creer muchos al pie de la letra los prodigios de las mentirosas historias de caballeros andantes (GONZÁLEZ SÁNCHEZ, 2007).

La aventura marítima posibilitó el conocimiento y la construcción de una diversa y diferente realidad. Los fines últimos de la humanidad, en la conciencia común, se van diluyendo en los horizontes que abren navegantes y conquistadores, artífices del triunfo de una nueva sensibilidad, regida por la razón y la experiencia, que despierta los sentidos y sus efectos inmediatos. El Renacimiento late en este vuelco de los conceptos de realidad y naturaleza, una diferente teoría del conocimiento que fluctúa desde las ideas a priori 
a lo empírico, haciendo de la experiencia personal el más fiable criterio de autoridad.

De este modo, en un universo lleno de realidades abstractas, se busca una pauta de lo verdadero e inapelable, capaz de superar la desconfianza en los sentidos como medio de conocimiento, incluso aplicado a fenómenos tangibles. Una actitud que lleva a Pedro Cieza de León (1518-1554), conquistador del Perú, a considerar semejantes acontecimientos dignos del relato de "un Tito Livio o Valerio, u otro de los grandes escritores que ha habido en el mundo; porque, ¿quién podrá decir las cosas grandes y diferentes que en él son, quién podrá contar los nunca oídos trabajos que han pasado" (CIEZA DE LÉON, 1985, p. 38). El humanista Gonzalo Fernández de Oviedo (1478-1557), a su vez, escribe altanero: "esto que he dicho no se puede aprender en Salamanca, ni en Boloña, ni en París” (FERNÁNDEZ DE OVIEDO, 1978, p. 45).

No es fortuito que tal cúmulo de extraordinarios sucesos se produjera en una época entusiasmada con la novedad, plena de primicias y en la que los hombres, queriendo emular a los antiguos, hicieron valer la sentencia omnia nova placet. El Atlántico es el abismo entre lo viejo y lo nuevo; a juicio de Jean de Léry (1534-1611), hugonote francés explorador en el Brasil de mediados del Quinientos, un espacio donde "todo lo que allí se ve, ya sea en la manera de vivir de los habitantes, en la forma de los animales, y en general en todo lo que produce la tierra, es diferente de lo que tenemos en Europa, Asia y África” (DE LÉRY, 1927, p. 83).

Ese recorrido a través de un mundo extraño predispuso una constante actitud de superación; así lo exótico o desconocido irá entrando de lleno en el ámbito de lo verosímil, pero sin anular del todo su confrontación con lo mágico, maravilloso e inexplicable. $\mathrm{El}$ aventurero del Renacimiento es un héroe ambicioso que ya no cuenta con una adversidad predestinada, sino sólo con la fortuna, su astucia, ingenio y una angustia constante. Su conciencia de dependencia de la fortuna, cambiante y caprichosa, deshace inmunidades e incrementa el miedo, el recelo, la inquietud y la ansiedad, todos símbolos de la muerte en unos escenarios ignotos, desconcertantes y a merced de la ventura. Hacía tiempo que los humanistas aconsejaron no confiar en la volubilidad y ligereza de la fortuna y, en 
cambio, aceptar el destino como una consecuencia directa de las actuaciones humanas.

El periodo de tiempo en cierne en España coincide con el auge del modelo colector de la Wunderkeammer o "cámara de maravillas". Si bien, el Renacimiento trajo consigo una noción de maravilla diferente a la de la Edad Media, época esta en la que se nutría de los sucesos extraordinarios de moda inspirados en los bestiarios y relatados por viajeros, sobrados en fantasía, a países imaginarios; o sea: equinocéfalos, cinocéfalos, faunos, cíclopes, mujeres barbudas, niños con dos cabezas, hombres con seis pies, sirenas o dragones. Las gemas y otras piedras curativas mencionadas en los textos sagrados y diversos productos naturales taumatúrgicos cotidianos en el concepto de colección de entonces, el tesoro; donde las reliquias acaparaban la posesión, el tacto o la mera visión de los fieles, una simbólica y valiosa "mercancía turística” dice U. Eco (2009, p. 155). El móvil de un constante flujo de peregrinaciones cuya meta solía ser la veneración de unos objetos de culto y miríficos dotados de una especial vinculación con lo sagrado, cual testimonios de la divinidad y la santidad procedentes de un pasado mítico, que dispensan salvoconductos a la eternidad. Felipe II en El Escorial tenía un armario grande en el que custodiaba miles de reliquias, al que acudía a diario para besar, con los ojos y los labios, alguna de ellas (MULCAHY, 2004).

Pero, desde finales del siglo XV, la maravilla empezará a ser algo real y no lo legendario encontrado en geografías lejanas y ficticias. Una nueva perspectiva laica y científica, naturalista antes que mística, cambia el gusto por unos portentos antes contemplados como signos premonitorios de acontecimientos excepcionales. Los animales inusitados y las gentes pasmosas que los medievales viajantes a lo desconocido creían presenciar, e interpretaban con sus referentes clásicos y mitológicos, serán la sustancia de una distinta indagación, al menos precientífica. De ahí que les trajeran a la memoria los monstruos mitológicos de la Antigüedad, cuya observación contribuyó de manera decisiva al desarrollo de las ciencias naturales.

El entusiasmo de la era renacentista por conocer más del mundo, abrió paso a un estado de ánimo pleno de expectación hacia lo alejado, exótico y raro (FUMAROLI, 2008). Los prodigios de la naturaleza fascinaban porque revelaban los misterios escondidos en 
el universo. Descubrir era viajar, tener la posibilidad de presenciar y averiguar geografías y cosas nuevas. Más allá de los abismos terrestres habitaban los arcanos y los mirabilia que durante tanto tiempo los antiguos recrearon y soñaron. El paraíso bíblico, colmado de bondades imperecederas, capaz de eliminar la permanente escasez de una existencia plagada de miserias espirituales y materiales. Maravillarse fue la respuesta inicial de los europeos frente a la realidad de los nuevos mundos, una experiencia emocional e intelectual ligada a las preocupaciones estéticas y filosóficas del discurso humanista. Esta mezcla de seducción y temor exigía la intervención de la experiencia en la representación de la relación entre una naturaleza admirable y bella y el horror de lo extraordinario.

En la escolástica, en cambio, los hechos singulares no conforman una fuente cierta de conocimiento, a lo sumo son curiosidades, aberraciones o excepciones de la norma. Aunque llegarían a ser científicos, normales y habituales, porque ocurrían y podían apreciarse a través de los sentidos. Sin embargo en el hombre del Renacimiento subyacía una memoria mítica llena de maravillas, otro de lo principales estímulos de las exploraciones y la búsqueda de lugares extraños y no vividos, de las ansias de contrastar el orbe conocido con los desconocidos (SOLER, 2003). Ahora la maravilla, según la definición del lexicógrafo Sebastián de Covarrubias (15391613), ya era "cosa que causa admiración por extraordinaria, y maravillarse ver sus efectos ignorando las causas" (DE COVARRUBIAS, 1995, p. 736). Aunque la recepción de la novedad favorecerá otros espejismos y excesos de imaginación en el pensamiento occidental (PEROCCO, 1997).

El Atlántico, pues, auspició una distinta noción de mirabilia, algo portentoso e inopinado, en un medio asombroso y sobrecogedor que puede ser verdad, y no lo fantástico e inadmisible de la mentalidad mágica imperante. La presencia de lo extranatural no sorprende, al contrario, es asimilada como parte integrante de la realidad que provoca admiración. La maravilla reside tanto en la inmediatez como en lo irreal, actuando sobre el imaginario social y su expresión lingüística y estética. Mas siempre, apostilla Covarrubias, provoca admiración por desconocerse el origen de sus efectos, es decir, su incomprensión es la causa del estupor y, en consecuencia, de la 
intriga del observador (GREENBLATT, 1991). Impresión similar a la de Antonio de Torquemada (c. 1507-1569) en su fabuloso Jardín de flores curiosas (Salamanca, 1570):

Es tan poderosa la naturaleza, y tan varia en sus cosas, y el mundo tan grande, que cada día vienen a nuestra noticia muchas novedades. Las cosas de admiración no las cuentes, que no saben todas gentes como son: porque diziendo entre simples e ignorantes se burlan de ellas. (DE TORQUEMADA, 1577, p. 4).

La misma esencia de lo maravilloso hace que se convierta en enigma oculto, en misterio insondable, propio de confines alejados, en el espacio y en el tiempo, de los que escaseen las noticias.

Las cámaras de maravillas o gabinetes de curiosidades, antepasados de nuestros museos de ciencias naturales, aspiraban a coleccionar todo lo que hay que conocer, o lo que tuviere aspecto de extraordinario e inaudito. Cosas extravagantes o hallazgos sorprendentes como animales raros, sus esqueletos, fetos deformados, órganos humanos en alcohol, piedras, conchas, taxidermias, estatuillas de bronce, mármol y otros materiales. Adminículos del culto pagano, amuletos, ídolos, candiles, anillos, campanillas, fósiles, rarezas de las Indias, artefactos, armas, pinturas, instrumentos musicales, relojes, astrolabios, telescopios, globos, esferas o sextantes (DASTON, 2004). Estos últimos, entonces de gran belleza, enseres decorativos y muy útiles en aquel mundo en expansión (IMPEY, MAC GREGOR, 1985). Eran auténticos museos en miniatura, el sueño del conocimiento científico total que Francis Bacon (1561-1626) representa utópicamente en su Nueva Atlántida (Londres, 1628), una isla-cámara de maravillas en sí misma, entregada a la averiguación de las causas y secretas nociones del planeta (BACON, 1985, p. 263).

Un fin que contribuiría al engrandecimiento de los límites de la mente humana y su capacidad creativa mediante la experiencia. Los impresores aprovecharon esta predisposición para estampar un alud de libros de temática exótica, aunque todavía imperaba el deseo general de unidad y orden en el conocimiento. La nueva ciencia estaba generando muchas más preguntas de las que era capaz de resolver. 
Lo maravilloso también adquiere una función compensadora ante la trivialidad y la escasez cotidianas. No en vano se localiza en edades áureas y paraísos terrenales donde rigen la abundancia de alimentos, la desnudez de sus habitantes, la riqueza, la libertad sexual y el ocio: el Dorado, islas afortunadas, los trópicos, el país de la canela, el Paititi o las Siete Ciudades de Cíbola. Un mundo al revés, pero en la vida real, repleto de bondades imperecederas capaces de colmar la permanente penuria de la existencia (BUARQUE, 2010). Es por ello que nada admirara más a los andaluces de la era de los descubrimientos que el maná de oro, plata y piedras preciosas desembarcado en los puertos atlánticos de la región.

El célebre Fray Bartolomé de las Casas (+1566) cuenta en su Historia General de las Indias que, siendo niño, presenció en su Sevilla natal las albricias del Nuevo Mundo que bullían en el puerto, calles y plazas de la ciudad. No pocas en boca de charlatanes sin medida, supuestos testigos de aquellas quimeras fronterizas. Unos nueve años tendría cuando Cristóbal Colón regresó de su primer viaje ultramarino, acontecimiento que, a su llegada a la urbe sevillana, se celebró con "una fiesta como la que se hace el día de Corpus Christi, que en muchos tiempos pasados cosas tan nuevas y diversas, festivas y de tanta solemnidad nunca fueron imaginadas". Al Almirante lo recuerda como "varón de grande ánimo", que traía consigo siete indios, lo más desconcertante para los espectadores, cuarenta papagayos verdes y colorados, guaizas - carátulas hechas de pedrería, aljófar y oro -, varias muestras autóctonas de árboles y plantas y "Otras muchas cosas nunca antes vistas en España ni oídas" (LAS CASAS, 1994, p. 25 et seq.).

Al estilo del huerto sevillano del médico Nicolás Monardes Alfaro (c. 1493-1588), hijo de Niculoso Monardis, librero de ascendencia genovesa activo en la Sevilla de principios del Quinientos. Nicolás, testigo directo de las sorpresivas nuevas americanas que arribaban en el puerto del Guadalquivir, quedó fascinado ante la "gran suma de millones" y voluminosa descarga de perlas, esmeraldas, turquesas, papagayos, monos, leones, gerifaltes, azores, tigres y, en particular, las plantas, yerbas, licores, raíces, árboles, frutos y simientes de grandes propiedades medicinales. El fundamento del museo natural que creó, uno de los primeros conocidos, en 1554 
alojado en la casa que acababa de comprar en la calle Sierpes, adonde lo trasladó desde la de los Francos. Los negocios mercantiles que mantenía con el Nuevo Continente, y la grata predisposición de sus factores y socios allí establecidos, siempre atentos a sus reclamos, le procuraron un exquisito surtido de semillas, piezas vegetales y substancias que los indios empleaban en la cura de enfermedades (MONARDES, 1569).

El hecho de recibirlas disecadas, no le impidió asumir el reto de tenerlas en vivo, tras aclimatarlas y reproducirlas, para estudiarlas y aplicarlas a la medicina. Con este propósito formó su "jardín botánico"; de plantas exóticas como el carlo sancto, las cuentas jaboneras, el copal, la caraña, la higuera del infierno, el palo santo, el guayacán, la china, el tabaco, la cañafístola, el mastuerzo, la verbena, el leucoma y un largo etcétera. La estela del vademécum que publicó en 1574. Entre sus pacientes había gente de la talla de la duquesa de Béjar, el arzobispo Cristóbal de Rojas y el duque de Alcalá. Este último también dueño de una prolija colección de curiosidades y maravillas, como el VI de Medina Sidonia, el de Arcos y el de Osuna (RODRÍGUEZ MARÍN, 1988).

Otro médico hispalense, Juan de Cárdenas (1563-1609), nacido en la villa de Constantina y desde temprana edad residente en México, en 1591 editó el tratado Problemas y secretos maravillosos de las Indias, por no dejar de dar crédito a "las maravillas y ocultos secretos" de las Indias apreciados in situ; que, escribe, "si los oyera Plinio quedara absorto y espantado" (DE CÁRDENAS, 1591, p. 37). Tras observar, entre otros muchos fenómenos inexplicables, que el zumo de la yuca si se bebe crudo mata, pero hervido beneficia al cuerpo, en tanto que el peyote enloquece y provoca alucinaciones fantasmagóricas. Además de las virtudes curativas del azogue, el chocolate, el maíz o la grana. Del Maluco, el veneno de toda la fruta que nace en su banda de poniente; y de Ormuz, según destacaban los portugueses, cangrejos que excitan la lujuria. Al igual, y desde tiempos atrás, las ventajas taumatúrgicas del cuerno del unicornio, el rinoceronte, que en la Sevilla del siglo XVI, a ciencia cierta, atesoraron algunos médicos, el marqués de Tarifa y la esposa de Hernán Cortés (GIL, 2011). Incluso el medio ambiente de las Indias influía en la condición de los inmigrantes europeos, como si fuese por influencia astral, pues 
solían degenerar en codicia, vagancia y otros vicios execrables. Los criollos, en cambio, acusaban ingenio vivo, trascendido y delicado.

Una acostumbrada vía de comunicación de dicha prodigalidad pervive todavía en las cartas que las gentes afincadas en el Nuevo Mundo enviaban a sus amigos y familiares de la Península. En ellas son persistentes los incentivos directos en forma de cantos de sirenas, reales o fingidos, o sea, llamadas de atención sobre semejante cornucopia americana. La propia existencia de las Indias, una maravilla en sí mismas, hubiera bastado para desencadenar esta ensoñación dinámica de la mejora social y la fortuna al alcance de la mano.

Así encontramos en las misivas cuantos modelos sean de desear, del tenor de la que desde Lima envía Sebastián Cabrera a su mujer en Sevilla (1576); en la que escribe: "Es la mejor tierra que calienta el sol en cristianos, porque no saben qué cosa es hambre, que no hay más que derramar el trigo y echarle agua, y hacerse un cañaveral de grano, que de una fanega cogen cincuenta”. De aquella otra que desde México remite Juan Cabeza a su hermano Manuel en Córdoba (1590): "En esta tierra no se sabe qué cosa es hambre, porque se coge trigo y maíz dos veces al año, y hay de todas las frutas de Castilla, donde no se echa de menos España, y así la gente pobre lo pasa mejor en esta tierra, porque mandan siempre y no trabajan personalmente". También la que Francisco Sanz dirige desde Potosí a su hermano en Cádiz (1587): "La carne es de balde, oro y plata no hay que decir que es como tierra. Es una gloria esta tierra, que no falta más del paraíso para ser cielo toda ella" (OTTE, 1988, p. 483).

El mito y la información particular surtieron efecto, como lo dirime el cronista Fernández de Oviedo (1978, p. 87) cuando dice:

Hubo muchos que vendieron los patrimonios y rentas, y haciendas que tenían y heredaron de sus padres; y otros algo menos locos, las empeñaron por algunos años, dejando lo cierto por lo dudoso, no teniendo en nada el galardón que esperaban, en comparación de lo que habían de adquirir y ganar en este camino.

La suerte y las capacidades debieron repartir, equitativamente, miserias y abundancias, éxitos y fracasos. 
Pese a ello aun no deja de admirarnos la asiduidad y aparente facilidad de aquellos desplazamientos intercontinentales, impronta que tampoco pasó desapercibida a sus coetáneos, quienes no daban crédito a lo que con embelesada sorpresa divisaban. Tal es, a principios del siglo XVII, la aturdida impresión del escritor Cristóbal Suárez de Figueroa (c. 1571-1644):

"Admira la facilidad con que se embarcan, sin más recámara y provisión que una camisa, para tan largo viaje, como es el de las Indias. Apenas se despiden de sus casas; pues con decir: "Ahí me llego", parten a Tierra Firme" (SUÁREZ DE FIGUEROA, 1988, vol. 2, 539).

El coleccionismo de la segunda mitad del siglo XVI, por tanto, suele ser la plasmación, exterior y microcósmica, del renovado interés por el avance de las ciencias en escena, en aras del ansiado y frustrante dominio de la naturaleza. En esta disyuntiva cualquier objeto podía formar parte de una colección, la clave de un ambiente donde lo misterioso y la excepción se transforman en un canon epistemológico (CHECA; MORÁN, 1985). Se trata de una actitud acumulativa, heredera de la tradición medieval, ecléctica y erudita, consecuencia de una novedosa inquietud frente al saber, la cultura y el arte. Desde esta perspectiva el contenido de la colección se aprecia de una manera autónoma e independiente de su finalidad práctica, porque en ella cobra mayor relevancia el sentido lúdico del arte y los libros, y de lo excepcional sobre lo normativo. La curiosidad y el placer estético conviven con la fruición de coleccionistas obsesionados con los inmediatos efectos emocionales y terrenales inherentes a la riqueza.

El repertorio en todo momento está abierto a su enriquecimiento, incluso de componentes perecederos e incongruentes, efecto no pocas veces del gusto compulsivo por el acopio sin límites ni metas definidas, más allá de su valor crematístico. Así sucedía con los símbolos inusuales de una historia sagrada, como las reliquias, o las gemas preciosas dotadas de sustancias mágicas - ópalo, crisopacio, berilo, ágata, diaspro. Sin duda estas prácticas reflejan el progresivo refinamiento de la Corte durante el Quinientos. No es casual que 
cuadros, libros y tapices alcancen una posición privilegiada en los palacios de aristócratas y príncipes entusiasmados con los studia humanitatis, elementos plásticos fundamentales en la ornamentación de las áridas y austeras residencias nobiliarias y en cualquier colección que se preciara. El mejor de los signos ostentatorios en la exhibición de la fortuna económica, la autoridad política y la dignidad social.

El reinado de Felipe II es el periodo de tiempo en el que cobran fuerza en España las colecciones según el fundamento de la "cámara de maravillas"; cuando estudios, camarines y gabinetes se pueblan de las artificialia y naturalia antes mencionadas, combinadas con ingredientes más característicos del tesoro medieval, caso de los relicarios y otros útiles de capillas y oratorios: estampas, libros de rezo y devoción e imágenes piadosas. Unos y otros contribuían a recrear un hábitat íntimo y personal, que los humanistas consideraban ideal para el estudio y el recogimiento. El impacto de América en Europa, y los avances científico-técnicos que facilitaron su descubrimiento, en buena medida laten en estas actitudes.

El Atlántico también se proyectaba en el Pacífico, ambos océanos, integrados en el Nuevo Continente, fueron el nexo de unión entre el lejano Oeste de Filipinas, China y Japón, con Europa y África, espacios hasta entonces casi en mutuo desconocimiento. No obstante quedarían globalizados en el mundo gracias a los intercambios comerciales entre unos y otros. La insaciable demanda asiática de plata americana logró conectar a la vieja Europa con las Indias y el fabuloso Oriente, mediante una red mundial de negocios, tratos y contratos.

Durante dos siglos Sevilla fue la capital de este complejo planetario. Los metales preciosos americanos y el tráfico de mercancías intercontinental la convirtieron en una gran metrópolis del mundo occidental, el punto de encuentro del Mediterráneo, el Norte de Europa, el Norte de África, América y la distante geografía oriental Oriente. La acumulación de rentas, ficticias o verdaderas, favoreció su conversión en una aclamada ciudad renacentista, asiento de excelsas obras de arte y la salida a escena de numerosos e insignes artistas, literatos, intelectuales; así como de una rancia nobleza y la variopinta y próspera burguesía de su vecindario. Baste mencionar al cronista Francisco de Medina (1516-1577), los poetas Fernando de 
Herrera (1534-1597) y Rodrigo Caro (1573-1647), el músico Francisco Guerrero (1528-1599), el pintor Pablo de Céspedes (1538-1608), los humanistas Juan de Mal Lara (1524-1571) y el canónigo Francisco Pacheco (1535-1599), tío del maestro de la pintura (1564-1644), del mismo nombre, promotor del joven Velázquez (1599-1660). Al arrimo de la navegación y las instituciones ultramarinas, los cosmógrafos y expertos en náutica Alonso de Chaves (1492-1586), Pedro de Medina (1493-1567) y Rodrigo Zamorano (1542-1623).

Mas también viciosa Babilonia acopio de miserias y desventuras a causa de los espejismos de la plata americana, a raudales desembarcada en las orillas de su río Guadalquivir (MORALES, 1977). Porque además de ricos negociantes, sabios y artistas de cualquier procedencia, albergaba una desmedida cuantía de pobres, pícaros y malentretenidos, bergantes y mujeres de mal vivir. Paisaje humano palmario en el Arenal y su tamaña mancebía, no menos en unas cárceles atestadas, de ahí que de Santa Teresa abominara de ella como añagaza de "pecados para afligir harto". Las noticias de viajeros, escritores y vecinos varios dan fe de la admiración que amasaba la sin par y genuina plaza de los mercaderes de fray Tomás de Mercado (c. 1530-1575), quien en las fechas escribía:

Tienen los comerciantes sevillanos contratación en todas las partes de la Cristiandad y aún en Berbería. A Flandes cargan lanas, aceites y bastardos; de allá traen todo género de mercerías, tapicería y librería. A Florencia envían cochinilla, cueros, traen oro hilado, brocados, sedas y de todas aquellas partes gran multitud de lienzos. En Cabo Verde tienen el trato de negros, negocio de gran caudal y de mucho interés. A todas las Indias envían grandes cargazones de toda suerte de ropa, traen de allá oro, plata, perlas y cueros en grandísima cantidad (MERCADO, 1571, p. 65).

Sevilla, en el imaginario del común yacía como otra tierra prometida para todo aquel, de España o de fuera, con deseos de medrar. Mateo Alemán (1547-1614) lo refrenda en su Guzmán de Alfarache: "tierra de Jauja bien acomodada para cualquier granjería, pues corría la plata en el trato de las gentes como el cobre en otras 
partes, y con poca estimación la dispensaban francamente" (ALEMÁN, 1983, p. 125). Si las expectativas no se cumplían siempre quedaba el recurso de emigrar a las Indias, una solución enunciada con exquisitez en El celoso extremeño de Miguel de Cervantes (15471616), buen conocedor de primera mano, de 1587 a 1600, de las cuitas y virtudes hispalenses:

\begin{abstract}
Viéndose pues, tan falto de dineros, y aun no con muchos amigos, se acogió al remedio a que otros muchos perdidos en aquella ciudad se acogen, que es el pasarse a las Indias, refugio y amparo de los deseperados de España... engaño común de muchos y remedio particular de pocos (CERVANTES, 1981, v. 2, p. 63).
\end{abstract}

En suma, el Atlántico, y su eje Sevilla-Lisboa, como lugar de coincidencia de civilizaciones, lo hicieron posible la lengua como vehículo de cohesión y la plata como objeto de cambio. Las bulas papales y los tratados de Alcaçovas-Toledo (1479-80) y el de Tordesillas (1494) quisieron hacer del Atlántico un Mare clausum para Castilla y Portugal. Pero potencias europeas ribereñas no cejaron hasta convertirlo en un Mare liberum (ELLIOTT, 2010). No obstante, españoles y portugueses lograron transformarlo en un nuevo Mare nostrum, como los romanos con el Mediterráneo (MARTÍNEZ SHAW, 2014). Así, y a partir de intercambios de todo tipo, alcanzó una unidad de costumbres y formas, impuestas y mixturadas, de entender el mundo (VILA, 2012).

El Asia oriental, sin embargo, se veía como unos confines demasiado alejados del solar andaluz, por ello sus habitantes tenían una muy leve idea de China y Japón, salvo los funcionarios, misioneros y soldados que llegaron a asentarse en aquellos reinos. Para el común de la población eran emplazamientos legendarios en las postrimerías de la Tierra, repletos de maravillas, tesoros y especias que, desde medidos del siglo XVI, se identificaban sin distinción con Filipinas. El referente oriental de España donde dos sevillanos ocuparon el cargo de gobernador. El primero Guido Lavezaris (15121582), entre 1572 y 1575, hasta entonces un joven librero, de origen genovés, al servicio de la imprenta sevillana de los Cromberger en 
México. El otro, de 1596 a 1602, el tesorero de la Casa de la Contratación Francisco Tello de Guzmán.

Como sucedió con los indios americanos, lo que más llamó la atención de los andaluces fueron los orientales, pocos, que recalaron en nuestra región, la mayoría en Sevilla y casi todos en calidad de esclavos, exotismos humanos que despertaban una pasmosa suspensión. Mas sabemos, gracias a los inventarios de bienes estudiados por Juan Gil, cómo a medida que Oriente se iba haciendo presente, las gentes garantes del nivel de vida pertinente se fueron aficionando al consumo de pimienta y otras especias; a tejidos finos y lujosos como el calicut, la sinabafa, el canequí, el balagate o el pacharí. No menos a vestidos, mantones y ropa doméstica de esmerada elaboración; lozas y porcelanas preciosas, abanicos, gemas, jaspe, rubíes y diamantes. A la vez de un exquisito y singular mobiliario de rica madera pintada y taracea: biombos, camas, mesas, bufetes, escritorios y escribanías (GIL, 2011). La mayor parte de lo enumerado en hogares de aristócratas, el alto clero y la burguesía en general.

El más encumbrado acontecimiento de esta secuencia oriental fue la embajada japonesa de Hasekura. Fruto del empeño del franciscano, y misionero en la tierra del Sol Naciente, Luis Sotelo, sevillano de la ilustre familia conversa de los Caballero, quien consiguió convencer al rey de Sendai, Date Masamune, para que, en 1613, enviase una representación diplomática a la corte de Felipe III y al Papa Paulo V. En estas cuitas, la delegación nipona, una vez superada la travesía del Pacífico, embarcó en Veracruz rumbo a España. Tras sobrevivir a la imprevisible y sempiterna singladura atlántica, la comitiva llegó a Sanlúcar de Barrameda el 30 de septiembre del año en cuestión. El duque de Medina Sidonia, enterado del arribo, le envió unas diestras y bien enjaezadas carrozas, que la llevarían al dadivoso alojamiento que había mandado preparar para darle la bienvenida y agasajarla. Días después aquellos embajadores remontaron el Guadalquivir hasta alcanzar Coria, donde fueron hospedados por el veinticuatro Pedro Galindo entre los vecinos del lugar. Finalmente pisan a Sevilla el 23 de octubre, ciudad en la que protagonizaron una solemnísima y engalanada entrada, obsequio del concejo hispalense, en todo momento resuelto en liberalidad con tan extraños huéspedes. Cabe apuntar, como bien se sabe, que 
algunos de aquellos nipones decidieron volver a Coria para radicarse allí, evento cuyas huellas todavía campean en el apellido Japón de por aquí (GIL, 2011).

Una llamada "nueva historia atlántica" acaricia la necesidad de insertar el Mundo Atlántico en el contexto más amplio de la "historia global”, el referente de la primera mundialización de los siglos XVI y XVII; cuando la plata americana y los intercambios comerciales de la Carrera de Indias lograron conectar Europa, a través de la América ibérica, con el Asia oriental. Para algunos este procedimiento metodológico podría solucionar muchos de los entresijos historiográficos hoy visibles. No obstante estimo más conveniente aspirar a una historia de toda América (española, portuguesa, inglesa, francesa y holandesa), encuadrada en una encrucijada atlántica compartida. La del Nuevo Mundo de los europeos, tal vez, capaz de superar una historiografía de las Américas empeñada en destacar diferencias y disparidades antes que los prolijos nexos de unión que el gran Océano ha venido conformando (ELLIOT'T, 2006).

Al hilo, la tradición historiográfica norteamericana se ha volcado en el estudio de las Trece Colonias como entes aislados - la mejor forma de crear una "nación de chovinistas" dice Elliott -, con el fin de resaltar su tipicidad, originalidad y diferencias respecto al resto del Continente; sin ser consciente de sus propias disimilitudes internas, de que Virginia también difiere de Nueva Inglaterra. A ello se debe que hasta hoy, el tratamiento de cada una de las colonias norteamericanas se suela afrontar mediante el estudio de sus diversas comunidades locales, la premisa, idealista y microscópica, de una historia nacional propiciatoria del excepcionalismo americano. El resultado, pues, ha sido una historia, sólo de blancos europeos, que exhibe el éxito del Norte frente al fracaso del Sur; aunque en realidad no fueran tantas las divergencias entre los dos hemisferios coloniales enfrentados.

Incluso hay quien interpreta la colonización puritana de Nueva Inglaterra como una continuación de los modelos ibéricos, y no cual la abrupta y novedosa ruptura que parece sugerir la historiografía empeñada en ver en las sociedades puritanas formaciones radicalmente diferentes a las instituidas en las Indias por el catolicismo español. Es más, Fernández Armesto (2003) demuestra cómo el 
Sur superó al Norte en términos demográficos, urbanos, políticos y culturales durante los siglos modernos, época en la que el primero tambiém gana en secularización e individualismo; y concluye: "El hemisferio occidental americano comienza a reducirse de tamaño tan pronto como acaba el periodo colonial británico-americano" (FERNÁNDEZ ARMESTO, 2003, p. 75 et seq.).

Lamentablemente, una historiografía latinoamericana presa de sí misma, desde la liberal del siglo XIX, viene asumiendo la retórica del declive, frente al Sur, de la norteamericana, un trágico discurso propio de la leyenda negra y sus tópicos que R. Kagan denomina el "paradigma Prescott". A William H. Prescott (1796-1859), en efecto, debemos la revitalización de la "leyenda negra" protestante para explicar el atraso del mundo hispánico y el meteórico auge de los Estados Unidos a lo largo de la Modernidad. Esta tendencia intenta contrarrestarla Herbert E. Bolton (1870-1953) desde 1933 promocionando una historia de América que superase las tradicionales perspectivas nacionales, en especial la de los Estados Unidos al margen del resto del Continente. Bolton, claro está, contribuyó a crear un clima contrario a estas descripciones simplistas y a favor de las realizaciones de los españoles en América, que sus discípulos desplegaron en monografías de impacto; entre ellos Irving. A. Leonard, el autor de Books of the brave, que prefirió cambiar el negro de la leyenda por un gris claro (LEONARD, 1979).

En los últimos años, sin embargo, está aumentando el número de historiadores, liderados por J. Elliott, dispuestos a reivindicar que la trayectoria histórica de Estados Unidos comparte los mismos problemas con otros lugares del mundo, asequibles desde presupuestos metodológicos abiertos y comparados. La historia de las Américas, por tanto, tiene un sentido más claro si se examina interrelacionando sus distintas partes $y$, antes que nada, como un todo indisociable fruto de un océano y un continente comunes. Una meta posible si convertimos al Atlántico, al igual que el Mediterráneo, en la auténtica bisagra de unión de las dos mitades del mundo, o sea, una viable y eficaz unidad de estudio para engullir los contextos nacionales de la historiografía ensimismada y provinciana. En este sentido, el enfoque transnacional y el método comparativo quizás nos presten un horizonte renovador y pleno de posibilidades. 
J. Cañizares-Esguerra, ferviente atlantistas, argumenta que la historia de las Américas es la historia de las grandes migraciones atlánticas y del contacto multicultural de europeos, indígenas y africanos, en una red de circuitos comerciales, intelectuales, culturales y políticos.

Elliott es rotundo cuando dirime que América, al igual que Europa, tiene una historia común, porque ambas desarrollan una la misma civilización y comparten experiencias y rasgos en un pasado donde las semejanzas prevalecen sobre las diferencias. Todo ello no impide la diversidad ni grandes diferencias de estructura y experiencia histórica, o admitir que la cultura americana no fue una réplica exacta de la europea. Ha llegado la hora, pues, de buscar el equilibrio entre las percepciones sobre el Norte y las del Sur, de superar unas perspectivas nacionalistas y patrióticas impulsoras del neopositivismo y, por la falta de integración del análisis historiográfico en marcos generales, de una historia tendenciosa empeñada en resaltar hechos diferenciales que limitan la amplitud de miras propia del conocimiento científico.

\section{THE ATLANTIC, PARADIGM OF NOVELTY IN THE RENAIS- SANCE AGE. IMAGINARY AND REALITY}

Abstract: The writing about the things of the New Worlds was the platform of the universal display informative during the Renaissance. The news of those events were essentials to the knowledge of the impact of those new civilizations in Europe. Then the Europeans was surprised by the discoveries of the new lands across the Atlantic and Pacific, may be the beginningn of the current Globalization. This is that why nowadays the historians are very interested for the origin of the that Global World, its wonders and realities in the Early Modern Era.

Keywords: Renaissance. Knowledge. Wonders. Information. Novelties. 


\section{Carlos Alberto González Sánchez}

\section{Notas}

${ }^{1}$ Este trabajo se inscribe dentro del Proyecto $\mathrm{I}+\mathrm{D}+\mathrm{I}$ Vida cotidiana, cultura gráfica y Reforma Católica en el Mundo Hispánico, Ref. HAR2014-52434-C5-3-P, del Ministerio de Economía y Competitividad.

${ }^{2}$ Una investigación de este cariz, con óptimos resultados, pero referida al Mediterráneo, es la que lleva a cabo (SOLA, 2005, 2006). Muy sugerente es, del mismo modo, el ensayo de Salinero (2005, p. 3-22).

\section{Referencias}

ALEMÁN, Mateo. Gurmán de Alfarache. Barcelona: Planeta, 1983.

ARES, Berta; GRUZINSKI, Serge (coords.). Entre dos mundos. Fronteras culturales y agentes mediadores. Sevilla: Escuela de Estudios Hispano-Americanos, 1997.

BACON, Francis. Nueva Atlántida. Madrid: Fondo de Cultura Económica, 1985. BUARQUE DE HOLANDA, Sérgio. Visâo do Paraíso. Os motivos edênicos no descobrimento e colonizaçâo do Brasil (1959). São Paulo: Companhia das Letras, 2010.

CAÑIZARES-ESGUERRA, Jorge. Cómo escribir la historia del Nuevo Mundo: historiografías, epistemologias e identidades en el mundo del Atlántico del siglo XVIII. México: Fondo de Cultura Económica, 2007.

CERVANTES, Miguel de. Novelas ejemplares. Madrid: Editora Nacional, 1981.

CIEZA DE LEÓN, Pedro. Crónica del Perú. Madrid: Orbis, 1985.

CHECA CREMADES, Fernando; MORÁN TURINA, Miguel. El coleccionismo en España. De la cámara de las maravillas a la galería de pinturas. Madrid: Cátedra, 1985.

DASTON, Lorraine. Things that Talk. Objects Lessons from Art and Science. Nueva York: Zone Books, 2004.

DE CÁRDENAS, Juan. Problemas y secretos maravillosos de las Indias. México: Pedro de Ocharte, 1591.

DE COVARRUBIAS, Sebastián. Tesoro de la lengua castellana o española. Madrid: Castalia, 1995.

DE LÉRY, Jean. Le voyage au Brésil de Jean de Léry: 1556-1558, edic. de Ch. Clerc. París: Payot, 1927. 
DE TORQUEMADA, Antonio. Iardin de flores curiosas, en que se tratan algunas materias de Humanidad, Philosophia, Teología, y Geographia, con otras cosas curiosas, y apacibles. Compuesto por Antonio de Torquemada. Salamanca: Alonso de Terranova, 1577. ECO, Umberto. El vértigo de las listas. Barcelona: Lumen, 2009.

ELLIOTT, John H. Imperios del Mundo Atlántico. España y Gran Bretaña en América (1492-1830). Madrid: Taurus, 2006.

ELLIOTT, John H. España, Europa y el mundo de ultramar (1500-1800). Madrid: Taurus, 2010.

FERNÁNDEZ ARMESTO, Felipe. The Americas: A Hemispheric History. New York: Ransom House, 2003.

FERNÁNDEZ DE OVIEDO, Gonzalo. Sumario de la Naturaly General Historia de las Indias. Madrid: Espasa-Calpe, 1978.

FOUCAULT, Michel. Des autres espaces. Heterotopías. En Dits et écrits, n ${ }^{\mathrm{a}} 5$, 1984, p. 46-49.

FUNAROLI, Marc. Las abejas y las arañas: la querella de los antiguos y modernos. Barcelona: El Acantilado, 2008.

GIL, Juan. La India y el Lejano Oriente en la Sevilla del Siglo de Oro. Sevilla: Ayuntamiento de Sevilla, 2011.

GIL, Juan. Historia de la embajada de Idate Masamune al Papa Paulo V (1613-1615). Madrid: Doce Calles, 2011.

GONZÁLEZ SÁNCHEZ, Carlos Alberto. Homo Viator, homo scribens. Cultura gráfica, información y gobierno en la expansión atlántica (siglos XV-XVII). Madrid: Marcial Pons, 2007.

GREENBBLATT, Stephen. Marvelous Possessions: The Wonder of the New World. Chicago: University of Chicago Press, 1991.

Gruzinski, Serge. El pensamiento mestižo. Barcelona: Paidós, 2007.

Gruzinski, Serge. Las cuatro partes del mundo: historia de una mundialización. México: Fondo de Cultura Económica, 2010.

IMPEY, O.; MAC GREGOR, A. The Origins of Meseums. The Cabinet of Curiosities in Sixteenth and Seventeenth Century Europe. Oxford: Clarendom Press, 1985.

LAS CASAS, Fray Bartolomé de. Historia de las Indias. Madrid: Alianza, 1994. v. 1, 2. LEONARS, Irving A. Los libros del conquistador. México: Fondo de Cultura Económica, 1979.

LOUREIRO, Rui M.; GRUZINSKI, Serge (eds.). Passar as fronteiras, II Coloquio Internacional sobre Mediadores Culturais, séculos XV a XVIII. Lagos: Centro Gil Eanes, 1999. 


\section{Carlos Alberto González Sánchez}

MARTINEZ SHAW, Carlos. España y Portugal en el mundo (1581-1668). Madrid: Polifemo, 2014.

MÁRTIR, Pedro. Epistolario. Madrid: DIHE, 1953-1957.

MÁRTIR, Pedro. Décadas del Nuevo Mundo. Madrid: Ediciones Polifemo, 1989.

MERCADO, Fray Tomás de. Suma de tratos y contratos. Sevilla: Hernando Díaz, 1571.

MONARDES, Nicolás. Historia medicinal de las cosas que se traen de nuestras Indias Occidentales que sirven en Medicina. Sevilla: Hernando Díaz, 1569.

MORALES PADRÓN, Francisco. La ciudad del Quinientos. Sevilla: Universidad de Sevilla, 1977.

MORO, Rafaelle. Viajes y movilidad en los discursos de vida y en las autobiografías en el mundo hispánico (siglos XVI-XVIII). In: . Passeurs, mediadores culturales y agentes de la primera globalización en el Mundo Ibérico, siglos XVI-XIX. Lima: Pontificia Universidad Católica del Perú, 2005, p. 107-126.

MULCAHY, Rosemarie. Philip II of Spain, Patron of the Arts. Dublín: Four Courts Press, 2004.

OTTE, Enrique. Cartas privadas de emigrantes a Indias, 1540-1616. Sevilla: Junta de Andalucía, 1988.

PEROCCO, Daria. Viaggiare y raccontare. Narrazione di viaggio ed esperienze di racconto Cinque e Seicento. Alessandria: Edizione dell'Orso, 1997.

RODRÍGUEZ MARÍN, Francisco. La verdadera biografía de Nicolás Monardes. Sevilla: Padilla Libros, 1988

RUSSELL-WOOD, John. The Portuguese Empire, 1415-1808. A World on the Move. Manchester: Carcanet, 1992.

SALINERO, Gregoire. Mobilité et identités dans les études de la relation Espagne -Amérique (XVIe-XVIIIe siècles). In: . Mezclado y sospechoso. Movilidad e identidades, España y América (siglos XVI-XVIII). Madrid: Casa de Velásquez, 2005, p. 3-22.

SOLA, Emilio. Los que van y vienen. Información y fronteras en el Mediterráneo clásico del siglo XVI. Madrid: Universidad de Alcalá de Henares, 2005.

SOLA, Emilio. Espionaje, información y cultura. Literatura de avisos en la época de Cervantes. In: CASADO, Manuel; CASTILLO, Antonio (eds.) Escrituras silenciadas en la época de Cervantes. Alcalá de Henares: Universidad de Alcalá de Henarea, 2006, p. 19-37.

SOLER, Isabel. El nudo y la esfera. El navegante como artifice del mundo moderno. Barcelona: El Acantilado, 2003. 
El Atlántico, paradigma de la novedad en la época...

SUÁREZ DE FIGUEROA, Cristóbal. El Pasajero. Madrid: PPU. 1988.

VILA VILAR, Enriqueta. Hispanismo e bispanización: el Atlántico como nuevo Mare Nostrum. Madrid: Real Academia de la Historia, 2012.

Recebido em: 22/12/2016 Aprovado em: 03/03/2017 